\title{
ANALISIS KEANDALAN DAN SUSUT DAYA PENYULANG TABANAN SETELAH REKONFIGURASI
}

\author{
Salman Al Farisi ${ }^{1}$, Rukmi Sari Hartati ${ }^{2}$, I Wayan Sukerayasa ${ }^{3}$ \\ Program Studi Teknik Elektro, Fakultas Teknik Universitas Udayana \\ Email: alfarisi salman1@yahoo.co.id ${ }^{1}$, rshartati@unud.ac.id $^{2}$, sukerayasa@unud.ac.id ${ }^{3}$
}

\begin{abstract}
Abstrak
Kebutuhan tenaga listrik di era global ini semakin bertambah, sehingga diperlukan sistem kelistrikan yang semakin handal. Sistem yang handal tidak terlepas dari gangguan sehingga perlu ada suatu analisis sistem keandalan dan susut daya pada penyulang dengan cara merekonfigurasi jaringan. Penelitian ini dilakukan untuk mencari nilai indeks keandalan berupa frekuensi gangguan dan lama gangguan (SAIFI dan SAIDI). Pada salah satu penyulang Tabanan hasil yang didapat melebihi standar sehingga dilakukan rekonfigurasi. Berdasarkan analisis didapatkan hasil sebelum rekonfigurasi, indeks keandalan untuk SAIFI adalah 6,7456 (gangguan/tahun) dan SAIDI 11,4767 (jam/tahun) dan susut daya 6,27\%. Setelah direkonfigurasi penyulang Tabanan indeks keandalan menjadi lebih baik, untuk SAIFI 5,2475 (gangguan/tahun) dan SAIDI 9,8798 (jam/tahun), susut daya $2,82 \%$. Penyulang Sanggulan adalah penyulang baru hasil rekonfigurasi dari penyulang Tabanan, dimana analisis yang dilakukan untuk mengetahui indeks keandalan penyulang Sanggulan didapat nilai SAIFI 4,5753 (gangguan/tahun) dan SAIDI 9,5297 (jam/tahun) dan susut daya 4,80\%.

Kata Kunci : Keandalan, Susut Daya, SAIFI, SAIDI, Rekonfigurasi
\end{abstract}

\begin{abstract}
The need for electricity in this global era is increasing, so that a more reliable electrical system is needed. A reliable system cannot be separated from interference, so there needs to be a system reliability analysis and power loss to the feeder by configuring the network. This research was conducted to find the reliability index value in the form of interference frequency and duration of interference (SAIFI and SAIDI). In one Tabanan feeder the results obtained exceed the standard so reconfiguration is performed Based on the analysis obtained before reconfiguration, the reliability index for SAIFI is 6,7456 (failure / year) and SAIDI is 11,4767 (hour / year) and power loss by 6,27 $\%$. After reconfiguration of Tabanan feeder, the reliability index was better, for SAIFI is 5.2475 (disturbance / year) and SAIDI is 9,8798 (hour / year), the power loss was 2.82\%. Sanggulan feeder is a new feeder reconfiguration result from Tabanan feeder, where the analysis was carried out to find out the reliability index of Sanggulan feeder, it was obtained the SAIFI value of 4.5753 (disturbance / year) and SAIDI of 9.5297 (hour / year) and power loss of 4,80\%.
\end{abstract}

Keywords: Reliability, Power Loss, SAIFI, SAIDI, Reconfiguration

\section{PENDAHULUAN}

Saat ini kebutuhan tenaga listrik telah menjadi kebutuhan pokok, sehingga kontinuitas penyediaan tenaga listrik menjadi tuntutan yang semakin besar dari konsumen. Maka perlu adanya suatu sistem tenaga listrik yang handal, keandalan merupakan faktor yang penting dalam suatu sistem distribusi tenaga listrik. Pertumbuhan beban listrik yang meningkat dengan pesat, maka PLN sebagai pemasok memenuhi kebutuhan tenaga listrik secara kontinu.
Susut daya pada sistem tenaga listrik tidak dapat dihindari dan akan selalu ada, namun susut daya dapat diminimalkan. Susut daya yang kecil menjaga pasokan daya listrik yang disalurkan sesuai dengan kebutuhan konsumen, serta dapat mengurangi kerugian finansial yang terjadi selama proses transmisi dan distribusi. Keandalan dapat dilihat dari lamanya pemadaman dan seberapa sering pemadaman terjadi dalam satu satuan waktu. Salah satu parameter keandalan sistem tenaga listrik adalah SAIDI dan SAIFI. PT PLN (Persero) Distribusi Bali saat ini telah 
mendeklarasikan diri sebagai perusahaan dengan pelayanan kelas dunia atau WCS (world class service), dimana beberapa parameter WCS untuk indeks keandalaan seperti SAIDI adalah 150 menit/ pelanggan /tahun dan SAIFI 3 kali/ pelanggan /tahun.

Jaringan distribusi merupakan bagian yang penting pada sistem kelistrikan. Dalam penyaluran tenaga listrik, jaringan distribusi berperan menghubungkan sistem transmisi dengan konsumen tegangan menengah 20 $\mathrm{kV}$ dan konsumen tegangan rendah 380/220 Volt. Penyaluran tenaga listrik ke konsumen sering mengalami kendala sehingga pelayanan terhadap konsumen tidak terpenuhi dengan baik. Semakin meningkatnya aktivitas kehidupan manusia akan mengakibatkan tingginya permintaan tenaga listrik. Penambahan beban bisa mengakibatkan penambahan suplai daya yang akan meningkatkan susut daya saat didistribusikan. Susut daya pada jaringan distribusi dapat dikurangi dengan melakukan rekonfigurasi jaringan distribusi.

Susut daya pada penyulang Tabanan sendiri tahun 2015 mencapai 6,27\% 2016 mencapai $6,50 \%$ dengan forcasting (5 years) tahun $20176,80 \%$, tahun $2018 \quad 7,10 \%$, sedangkan pada tahun 2021 mencapai $7,70 \%$ [1]. Berdasarkan hasil forcasting ini maka penyulang Tabanan perlu dilakukan rekonfigurasi jaringan.

\section{Kualitas Daya Listrik}

Kualitas daya listrik ditentukan oleh kualitas arus, tegangan, frekuensi, harmonisa, susut daya, faktor daya, pentanahan (grounding), serta kesetimbangan sistem. Masalah kualitas daya listrik adalah persoalan perubahan arus, tegangan atau frekuensi yang bisa menyebabkan kegagalan atau kesalahan, baik peralatan milik PLN maupun milik konsumen [2].

\subsection{Indeks Keandalan}

Indeks keandalan merupakan suatu indicator keandalan yang dinyatakan dalam suatu besaran probabilitas. Evaluasi keandalan sistem distribusi terdiri dari indeks titik beban dan indeks sistem, yang dipakai untuk memperoleh pengertian yang mendalam ke dalam keseluruhan capaian.
Indeks kegagalan titik beban yang biasanya digunakan meliputi tingkat kegagalan $\lambda$ (kegagalan/tahun), rata-rata waktu keluar (outage) $r$ (jam) dan rata-rata ketidaktersediaan tahunan $\cup$ (jam/tahun) [4][5].

Untuk menghitung indeks keandalan titik beban dan indeks keandalan sistem yang biasanya di gunakan meliputi angka keluar dan lama perbaikan dari masing - masing komponen [4][5].

\section{Pemadaman (Outage)}

Adalah keandalan dimana suatu komponen titik dapat berfungsi sebagaimana mestinya, diakibatkan karena beberapa peristiwa yang berhubungan dengan komponen tersebut. Suatu pemadaman dapat atau tidak menyebabkan pemadaman, hal ini masih tergantung pada konfigurasi dari sistem [3].

2. Lama Keluar (Outage duration)

Periode dari saat permulaan komponen keluar sampai saat komponen dapat dioperasikan kembali sesuai dengan fungsinya [3].

Sedangkan indeks keandalan yang dianalisis adalah SAIFI dan SAIDI.

\subsubsection{System Average Interuption Frequency Index (SAIFI)}

SAIFI merupakan jumlah rata-rata kegagalan per pelanggan yang dilayani per tahun. SAIFI didapatkan dengan membagi jumlah semua kegagalan pelanggan dalam satu tahun dengan jumlah pelanggan tersebut [3], dan di tetapkan dalam persamaan berikut.

$$
S A I F I=\frac{\sum \lambda_{i} \cdot N_{i}}{\sum N_{i}}
$$

Keterangan :

SAIFI adalah System Average Interruption Frequency Index

$\lambda_{1}$ adalah laju kegagalan komponen pada load point $i$

$\mathrm{N}_{\mathrm{i}}$ adalah jumlah pelanggan pada load point $i$

\subsubsection{System Average Interruption Duration Index (SAIDI)}

SAIDI merupakan nilai rata dari lamanya kegagalan per pelanggan yang dilayani dalam satu tahun. SAIDI didapatkan dengan 
membagi jumlah lamanya kegagalan pelanggan selama periode waktu tertentu dengan jumlah pelanggan yang dilayani selama tahun [3]. didapatkan persamaan sebagai berikut:

$$
S A I D I=\frac{\sum U_{i} \cdot N_{i}}{\sum N_{i}}
$$

Keterangan :

$\sum \lambda_{i} . N_{i} \quad$ adalah jumlah perkalian antara failure rate dengan jumlah pelanggan komponen $i$.

$\sum U_{i} \cdot N_{i} \quad$ adalah jumlah perkalian antara durasi kegagalan / unavailability dengan jumlah pelanggan komponen $i$.

\subsection{Susut Daya}

Sistem daya listrik yang di kirim dari sumber pembangkit listrik ke beban akan mengalami susut, disamping susut tegangan maka akan didapat pula susut daya, [4] yaitu

$$
\Delta \mathrm{P}=3 \times \mathrm{I}^{2} \times \mathrm{R}_{\text {efektif }}
$$

Keterangan :

$\Delta \mathrm{P}$ adalah Susut daya (KW)

I adalah Arus yang mengalir (Ampere)

$\mathrm{R}_{\text {efektif }}$ adalah Resistansi saluran efektif (Ohm/Km)

Jika susut daya telah diperoleh maka besar persentase kerugian daya dapat dihitung dengan persamaan berikut [5]

$$
\% \mathrm{P}_{\text {loss }}=\frac{P_{\text {loss }}}{P} \times 100 \%
$$

Keterangan :

$\mathrm{P}_{\text {loss }}$ adalah Susut daya (Watt)

$\mathrm{P}$ adalah Besar daya yang disalurkan (Watt, kW,MW)

\section{METODE PENELITIAN}

\subsection{Analisis Data}

Penelitian ini langkah pertama yang harus dilakukan adalah mencari dan mengumpulkan data yang berhubungan tentang keandalan dan susut daya penyulang Tabanan. Selanjutnya menggambar single line diagram di ETAP powerstation 12.6 sebelum dan setelah rekonfigurasi dan memasukkan data nilai masing-masing komponen mulai dari transformator daya di GI Kapal, busbar, penghantar, transformator distribusi, data pengaman dan beban pada penyulang Tabanan sebelum rekonfigurasi. Selanjutnya Program ETAP disimulasikan sebelum rekonfigurasi dengan cara mengeksekusi program dengan memilih menu toolbar running Reliability Assessment. Setelah di running kemudian memilih menu "Report Manager" untuk mengetahui hasil analisis indeks keandalan SAIFI dan SAIDI, setelah mengetahui hasil indeks keandalan lalu pilih menu "report manager" untuk mengetahui hasil nilai susut daya. Selanjutnya penyulang Tabanan direkonfigurasi dan di analisis kembali seperti sebelumnya.

\section{Hasil Dan PEMBAHASAN}

\subsection{Gambaran Umum Penyulang Tabanan}

Penyulang Penyulang Tabanan yang disuplai dari Gardu Induk Kapal merupakan salah satu penyulang yang melayani pendistribusian tenaga listrik di kawasan Tabanan dan sekitarnya. Penyulang Tabanan memiliki panjang 29,721 kms.

Penyulang Tabanan menyuplai beban sebagian besar adalah pelanggan tegangan rendah (rumah tangga). Kondisi penyulang Tabanan memiliki data-data sebagai berikut:

1. Kapasitas trafo : $14.445 \mathrm{kVA}$

2. Jumah transformator: 69 Unit

3. Konfigurasi jaringan : Sistem Radial.

4. Jenis penghantar : Campuran.

Dapat kita lihat di Tabel 1 dan Tabel 2 data penghantar dan data kapasitas trafo

\begin{tabular}{|c|c|c|}
\hline TIPE JTM & JENIS PENGHANTAR & PANJANG (KMS) \\
\hline \multirow{2}{*}{ SUTM } & AAAC $157.6 \mathrm{MM} 2$ & 28,570 \\
\hline & Total & 28,570 \\
\hline \multirow{5}{*}{ SKUTM } & MVTIC 20 KV NF A2XSEY - T3X150+95 mm2 & 0,113 \\
\hline & Total & 0,113 \\
\hline & XLPE $3 \times 240$ mm2 & 1,037 \\
\hline & Total & 1,037 \\
\hline & Total Panjang Penyulang & 29,721 \\
\hline
\end{tabular}
penyulang Tabanan.

Tabel 1. Data Penghantar P. Tabanan 
Data kapasitas trafo dan data daya terpakai dapat dilihat pada Tabel 2 dan Tabel 3 sebagai berikut.

Tabel 2 No Gardu 1-35, Kapasitas Trafo dan Daya Terpakai

\begin{tabular}{|c|c|c|c|}
\hline No & NO GARDU & $\begin{array}{l}\text { KAPASITAS TRAFO } \\
\text { (kVA) }\end{array}$ & $\begin{array}{l}\text { DAYA TERPAKAI } \\
\text { (kVA) }\end{array}$ \\
\hline 1 & T-KD0001 & 250 & 121 \\
\hline 2 & T-KD0002 & 250 & 169 \\
\hline 3 & T-KD0005 & 100 & 83,3 \\
\hline 4 & T-KD0006 & 100 & 50,3 \\
\hline 5 & T-KD0007 & 250 & 120 \\
\hline 6 & T-KD0008 & 250 & 99 \\
\hline 7 & T-KD0009 & 250 & 179 \\
\hline 8 & T-KD0038 & 250 & 132 \\
\hline 9 & T-KD0056 & 100 & 134 \\
\hline 10 & T-KD0063 & 250 & 100 \\
\hline 11 & T-KD0067 & 160 & 107 \\
\hline 12 & T-KD0068 & 160 & 39,7 \\
\hline 13 & T-KD0071 & 250 & 143 \\
\hline 14 & T-KD0073 & 100 & 63,8 \\
\hline 15 & T-KD0074 & 200 & 57,5 \\
\hline 16 & T-KD0079 & 160 & 111 \\
\hline 17 & T-KD0084 & 200 & 97,7 \\
\hline 18 & T-KD0092 & 400 & 281 \\
\hline 19 & T-KD0095 & 160 & 19,8 \\
\hline 20 & T-KD0096 & 160 & 29,2 \\
\hline 21 & T-KD0101 & 250 & 117 \\
\hline 22 & T-KD0111 & 100 & 71,8 \\
\hline 23 & T-KD0114 & 100 & 79,5 \\
\hline 24 & T-KD0116 & 250 & 96,8 \\
\hline 25 & T-KD0117 & 160 & 77,9 \\
\hline 26 & T-KD0118 & 160 & 75,5 \\
\hline 27 & T-KD0123 & 100 & 27,7 \\
\hline 28 & T-KD0124 & 200 & 7,3 \\
\hline 29 & T-MI0213 & 160 & 25,2 \\
\hline 30 & T-MI0237 & 100 & 3,3 \\
\hline 31 & T-TB0001 & 250 & 117 \\
\hline 32 & T-TB0002 & 250 & 46,1 \\
\hline 33 & T-TB0003 & 250 & 110 \\
\hline 34 & T-TB0004 & 250 & 155 \\
\hline 35 & T-TB0005 & 250 & 118 \\
\hline
\end{tabular}

Single Line Diagram Penyulang Tabanan

Berikut Gambar 1 adalah single line diagram penyulang Tabanan :
Tabel 3 No Gardu 36-69, Kapasitas Trafo dan Daya Terpakai

\begin{tabular}{|c|c|c|c|}
\hline No & NO GARDU & $\begin{array}{c}\text { KAPASITAS TRAFO } \\
\text { (kVA) }\end{array}$ & $\begin{array}{c}\text { DAYA TERPAKAI } \\
\text { (kVA) }\end{array}$ \\
\hline 36 & T-TB0006 & 250 & 151 \\
\hline 37 & T-TB0009 & 250 & 172 \\
\hline 38 & T-TB0016 & 250 & 118 \\
\hline 39 & T-TB0017 & 250 & 127 \\
\hline 40 & T-TB0018 & 250 & 178 \\
\hline 41 & T-TB0019 & 200 & 113 \\
\hline 42 & T-TB0021 & 500 & 88,3 \\
\hline 43 & T-TB0021P & 630 & 504 \\
\hline 44 & T-TB0041 & 250 & 198 \\
\hline 45 & T-TB0042 & 250 & 77 \\
\hline 46 & T-TB0046 & 160 & 32,1 \\
\hline 47 & T-TB0051 & 250 & 122 \\
\hline 48 & T-TB0053 & 250 & 40,6 \\
\hline 49 & T-TB0054 & 200 & 76,8 \\
\hline 50 & T-TB0057 & 315 & 63,4 \\
\hline 51 & T-TB0064 & 160 & 51,4 \\
\hline 52 & T-TB0065 & 250 & 148 \\
\hline 53 & T-TB0067 & 250 & 104 \\
\hline 54 & T-TB0069 & 100 & 56,6 \\
\hline 55 & T-TB0072 & 100 & 80 \\
\hline 56 & T-TB0073 & 100 & 31,1 \\
\hline 57 & T-TB0077 & 160 & 85.4 \\
\hline 58 & T-ТВ0079P & 630 & 507 \\
\hline 59 & T-TB0085 & 100 & 31,8 \\
\hline 60 & T-TB0086 & 160 & 118 \\
\hline 61 & T-TB0087 & 160 & 92,4 \\
\hline 62 & T-TB0089 & 160 & 69,1 \\
\hline 63 & T-TB0091 & 160 & 96,8 \\
\hline 64 & T-TB0093 & 100 & 47 \\
\hline 65 & T-TB0098 & 160 & 128 \\
\hline 66 & T-TB0099 & 160 & 86,1 \\
\hline 67 & T-TB0104 & 250 & 74,2 \\
\hline 68 & T-TB0109 & 100 & 42,7 \\
\hline 69 & T-TB0112 & 100 & 3,4 \\
\hline \multicolumn{2}{|c|}{ TOTAL } & 14.445 & $5.300,4$ \\
\hline
\end{tabular}




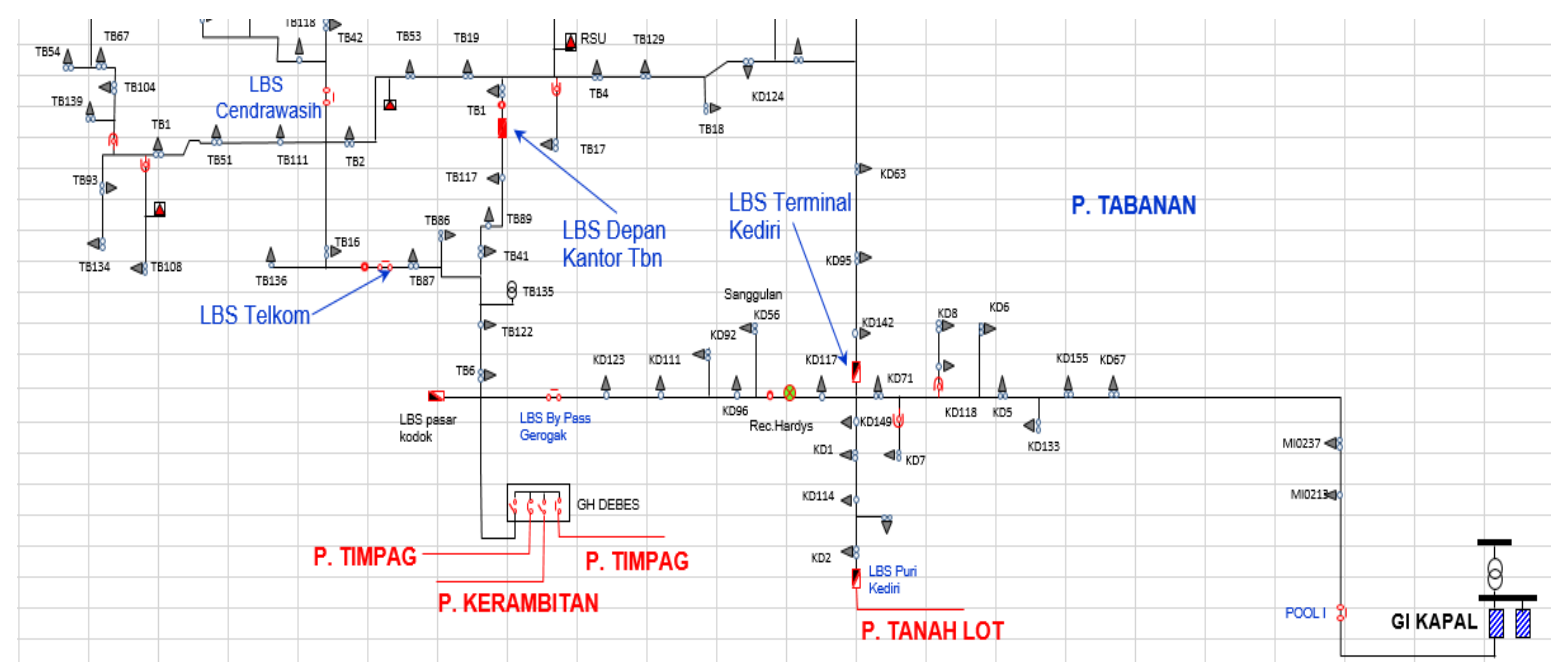

Gambar 1. Single Line Diagram Penyulang Tabanan

Single line diagram ini digunakan sebagai acuan untuk menggambar single line diagram di ETAP.

\subsection{Model Keandalan Yang Dianalisis}

Berikut adalah failure rate dari komponen sistem distribusi :

Tabel 4. Perkiraan Angka Keluar Sistem Distribusi

\begin{tabular}{|l|l|}
\hline KOMPONEN / PERALATAN & $\begin{array}{c}\text { FAILURE RATE }(\boldsymbol{\Lambda}) \\
\text { (FAIL/OUT/RATE) }\end{array}$ \\
\hline Saluran Udara & $0,2 / \mathrm{Km} /$ Tahun \\
Kabel Saluran Bawah Tanah & $0,07 / \mathrm{Km} /$ Tahun \\
Pemutus Tenaga & $0,004 / \mathrm{Km} /$ Tahun \\
Saklar Beban & $0,003 / \mathrm{Km} /$ Tahun \\
Saklar Pemisah & $0,003 / \mathrm{Km} /$ Tahun \\
Penutup Balik & $0,005 / \mathrm{Km} /$ Tahun \\
Penyambung Kabel & $0,001 / \mathrm{Km} /$ Tahun \\
Trafo Distribusi & $0,005 / \mathrm{Km} /$ Tahun \\
Pelindung Jaringan & $0,005 / \mathrm{Km} /$ Tahun \\
Rel Tegangan Rendah & $0,001 / \mathrm{Km} /$ Tahun \\
\hline
\end{tabular}

Sumber: (SPLN 59, 1985)

Perkiraan angka keluar ini yang akan dipakai di data masukan untuk program ETAP sebagai standar PLN.

\subsection{Indeks Keandalan Penyulang Tabanan sebelum dan setelah Rekonfigurasi}

Indeks keandalan dan ketersediaan sistem penyulang Tabanan sebelum dan setelah rekonfigurasi dapat di lihat pada Tabel 4 sebagai berikut:

Tabel 5. Hasil Indeks Keandalan Sebelum dan Setelah Rekonfigurasi

\begin{tabular}{c|l|l|}
\multirow{3}{*}{$\begin{array}{c}\text { Sebelum } \\
\text { Rekonfigurasi }\end{array}$} & SAIFI & 6,7456 (gangguan/tahun) \\
\cline { 2 - 3 } & SAIDI & 11,4767 (jam/tahun) \\
\cline { 2 - 3 } & CAIDI & 1,701 (jam/ganguan) \\
\cline { 2 - 3 } &
\end{tabular}

\begin{tabular}{|l|l|l|} 
& ASAI & $0,9987 \mathrm{pu}$ \\
\cline { 2 - 3 } & ASUI & $0,00131 \mathrm{pu}$ \\
\hline \multirow{4}{*}{$\begin{array}{c}\text { Setelah } \\
\text { Rekonfigurasi }\end{array}$} & SAIFI & 5,2475 (gangguan/tahun) \\
\cline { 2 - 3 } & SAIDI & 9,8798 (jam/tahun) \\
\cline { 2 - 3 } & CAIDI & 1,883 (jam/ganguan) \\
\cline { 2 - 3 } & ASAI & $0,9989 \mathrm{pu}$ \\
\cline { 2 - 3 } & ASUI & $0,00113 \mathrm{pu}$ \\
\hline
\end{tabular}

Berdasarkan hasil indeks keandalan Penyulang Tabanan sebelum dan setelah rekonfigurasi masih belum memenuhi standar WCS yaitu nilai SAIFI 3 kali gangguan/tahun dan SAIDI 150 menit/pelanggan/tahun.

\subsubsection{Susut Daya Penyulang Tabanan Sebelum dan Setelah Rekonfigurasi}

Berdasarkan hasil analisis didapat nilai susut daya Penyulang Tabanan sebelum dan setelah rekonfigurasi

Tabel 6. Susut Daya Penyulang Tabanan Sebelum dan Setelah Rekonfigurasi

\begin{tabular}{|c|c|c|}
\hline \multirow{2}{*}{$\begin{array}{c}\text { Penyulang } \\
\text { Tabanan Sebelum }\end{array}$} & \multicolumn{2}{|c|}{ Susut Daya } \\
\cline { 2 - 3 } Rekonfigurasi & kW & kVAR \\
\cline { 2 - 3 } & 411,2 & 529,0 \\
\hline \multirow{2}{*}{$\begin{array}{c}\text { Penyulang } \\
\text { Tabanan Setelah } \\
\text { Rekonfigurasi }\end{array}$} & \multicolumn{2}{|c|}{ Susut Daya } \\
\cline { 2 - 3 } & 74,5 & kVAR \\
\cline { 2 - 3 } & &
\end{tabular}

Berdasarkan hasil susut daya pada Tabel 6 dapat dilihat bahwa penyulang Tabanan setelah direkonfigurasi mengalami 
penurunan susut daya yang signifikan, dapat dilihat pada lampiran 3 dan lampiran 4 .

\subsection{Penyulang Sanggulan}

Penyulang Sanggulan adalah penyulang baru hasil rekonfigurasi dari penyulang Tabanan.

\subsubsection{Indeks Keandalan Penyulang Sanggulan}

Dapat di lihat hasil nilai indeks keandalan penyulang Tabanan pada Tabel 7 sebagai berikut.

Tabel 7. Indeks Keandalan Penyulang Tabanan

\begin{tabular}{|l|l|l|}
\hline \multirow{4}{*}{$\begin{array}{l}\text { Penyulang } \\
\text { Sanggulan }\end{array}$} & SAIFI & 4,5753 (gangguan/tahun) \\
\cline { 2 - 3 } & SAIDI & 9,5297 (jam/tahun) \\
\cline { 2 - 3 } & CAIDI & 2.083 (jam/ganguan) \\
\cline { 2 - 3 } & ASAI & $0.9989 \mathrm{pu}$ \\
\cline { 2 - 3 } & ASUI & $0,00109 \mathrm{pu}$ \\
\hline
\end{tabular}

Penyulang Sanggulan memiliki nilai SAIFI 4,5753 (gangguan/tahun) ini artinya dalam 12 bulan memilik peluang terjadi gangguan 8 sampai 9 kali dan SAIDI 9,5297 (jam/tahun) yang artinya dalam satu tahun rata-rata dari lamanya kegagalan pada sistem 9,5297 jam.

\subsubsection{Susut Daya Penyulang} Sanggulan

Hasil analisis susut daya penyulang Sanggulan dapat dilihat pada Tabel 8 sebagai berikut:

Tabel 8. Susut Daya Penyulang Sanggulan

\begin{tabular}{|l|c|c|}
\hline \multirow{2}{*}{$\begin{array}{l}\text { Penyulang } \\
\text { Sanggulan }\end{array}$} & \multicolumn{2}{|c|}{ Susut Daya } \\
\cline { 2 - 3 } & kW & kVAR \\
\cline { 2 - 3 } & 184,3 & 328,1 \\
\hline
\end{tabular}

Berdasarkan hasil susut daya penyulang Sanggulan dapat di katakan handal di karenakan saat penyulang Tabanan sebelum direkonfigurasi memiliki susut daya 411,2 kW, bisa di lihat pada Tabel 6 ,

\section{SIMPULAN}

Berdasarkan simpulan hasil analisis dan pembahasan yang dilakukan adalah sebagai berikut:

1. Analisis keandalan penyulang Tabanan saat kondisi eksisting dengan target WCS yang dicanangkan PLN, maka untuk SAIFI 6,7456 (gangguan/tahun) penyulang Tabanan belum tercapai, begitu juga dengan SAIDI 11,4767 (jam/tahun) juga belum tercapai.

2. Berdasarkan analisis yang dilakukan setelah rekonfigurasi jaringan, pada Penyulang Tabanan indeks keandalan dan ketersediaan semakin membaik dari sebelumnya karena sudah direkonfiurasi. Untuk penyulang Tabanan setelah rekonfigurasi nilai SAIFI 5,2475 (gangguan/tahun) dan SAIDI 9,8798 (jam/tahun) masih belum mencapai target WCS.

3. Hasil analisis susut daya penyulang Tabanan memiliki total susut daya sebesar 411,2 kW (6,27\%) saat kondisi eksisting, setelah di rekonfigurasi, Penyulang Tabanan memiliki total susut daya $74,5 \mathrm{~kW}(2,82 \%)$. dan penyulang baru yaitu penyulang Sanggulan memilik total susut daya $184,3 \mathrm{~kW}(4,80 \%)$. Dapat disimpulkan bahwa penyulang Tabanan setelah di rekonfigurasi mengalami penurunan susut daya yang signifikan.

\section{DAFTAR PUSTAKA}

[1] "MPSD BALI 2016-2021.pdf." .

[2] Alexander Kusko and Marc T. Thompson, Power Quality in Electrical Systems, 1st Edition. 2007.

[3] R.N. Allan and Billinton, Reliability Evaluation of Power Systems. 1996.

[4] Turan Gonen, Electric Power Distribution System Engineering, Second Edition. 1986.

[5] Miguel Nazario, Rukmi Sari Hartati, and I.W. Sukerayasa, "Analisis Keandalan Dan Susut Daya Pada Penyulang Vi Di Kota Dili Timor Leste," vol. Vol 1 No 1, no. Jurnal IImiah SPEKTRUM, 2014. 